\title{
Slenderness Ratio Influence on the Structural Behavior of Residential Concrete Tall Buildings
}

\author{
Tarek A. Awida \\ Faculty of Engineering, Ain Shams University, Cairo, Egypt
}

\begin{abstract}
The main concern of this paper is to study the influence of the building slenderness ratio on the structural behavior of the residential concrete tall buildings aiming to deepen structure and architect designers understanding for such type of buildings. The study is emphasized only on Kuwait city design conditions for wind and seismic loadings. The paper presents an actual case study for adding two thirty stories residential towers with two different slenderness ratios to an existing residential complex. Wind loading is considered using both code values and wind tunnel results. Three dimensional finite element techniques through ETABS software are used in conducting analysis for structures presented here. A serviceability study is performed to ensure that buildings have sufficient stability to limit lateral drift and peak acceleration within the acceptable range of occupancy comfort. In addition, an ultimate strength study is carried out to verify that all the structural elements are designed to withstand factored gravity and lateral loads in a safe manner according to the international building codes. Analysis results are presented and discussed. A brief idea about foundation design of the new towers and its connection to the existing foundation is presented. Finally conclusions are summarized as guidelines for the structural professions of concrete residential tall buildings.
\end{abstract}

Key words: Slenderness ratio, residential tall buildings, finite element, reinforced concrete analysis and design.

\section{Introduction}

In the last decade developers and authorities in Kuwait recognized the need to allow for more building heights due to many reasons. Some of these reasons were the increasing demand in the local market for office and residential areas, availability of the financial resources in safe and good economic conditions after the gulf War II and the aim to develop Kuwait city following Dubai model. It should be mentioned that the recent financial crisis has only minor effect on Kuwait economy since it depends mainly on the oil exporting which nearly kept in a reasonable price these days. In the time being, many high-rise buildings were already found in Kuwait city and many more are under design or construction. This situation forced the structural engineering professions

Corresponding author: Tarek A. Awida, PhD, assistant professor, research fields: three-dimensional finite element modeling, analysis and design of concrete structures, response of concrete tall buildings subjected to wind loadings, structural assessment and repair of concrete structures and value engineering. E-mail: tarek.awida@gmail.com. in Kuwait to expand their knowledge and advance their design and construction skills and techniques to be familiar with analysis and design of high-rise buildings [1]. The case study of residential complex in Kuwait city presented here can be considered as a good example to be studied and reported. It is an existing complex located near the Gulf road including basement and podium levels covering the whole plot area and above ground, there is eight buildings with different heights ranging from five to eighteen floors. The developers plan to construct two new thirty floors towers within the same property and in close proximity to the existing buildings to get benefited from the new regulations which allow for more building heights and more built-up areas in the residential buildings in Kuwait city. This paper provides brief description for the analysis and design procedure of these towers which have different slenderness ratios of 4.77 and 8.60. The influence of the building slenderness ratio on the behavior of the concrete tall buildings is demonstrated through this 
actual case study. The study was performed on reinforced concrete and emphasized only on Kuwait City design conditions for wind, seismic and soil conditions. Wind loading was considered using both code values and wind tunnel test results and the difference between them was presented. Three dimensional finite element analysis using ETABS software [2] which was originally developed by Computer and Structure Incorporation (CSI) used for conducting analysis and design of different structures presented in this study. This software was originally established with emphasize of tall buildings and widely used in the engineering design practice all over the world and especially in the Gulf area. A serviceability study was performed in order to ensure that buildings have sufficient stability to limit both the lateral drift and the peak acceleration at the highest occupied level within the acceptable range of occupancy comfort. In addition, an ultimate strength study was carried out to verify that buildings were designed to withstand factored gravity (dead plus live) and lateral (wind plus seismic) loadings in a safe manner according to the international building codes. Finally, analysis results for this study was presented and conclusions are summarized as guidelines for structural and architectural professions to be considered in the design practice of tall concrete residential buildings in Kuwait.

\section{Existing Site Conditions}

The existing development located near the Gulf road in Kuwait city and was constructed since 1978 as a residential complex. The foot-print of the site is 12,320 $\mathrm{m}^{2}$ and occupied entirely by a single level basement, which is used for car parking and electro-mechanical rooms. The podium is level mainly used for open space as entrances below the residential buildings while other areas as open to sky landscape including kids playground, gardens and pool. Above podium level, there were eight buildings with different heights ranging from five to eighteen floors. Solid slabs with beams are used as the structural floor system for the existing buildings while waffle slabs of $570 \mathrm{~mm}$ overall rib thickness are used in podium level to support the heavy loads of landscape and pool areas. Expansion joints are provided between the existing buildings and the other podium structure using continuous ledge or corbel scheme. The existing buildings foundation was $1500 \mathrm{~mm}$ thick raft while the podium structure was supported on spread footings of $1500 \mathrm{~mm}$ thick and connected by $300 \mathrm{~mm}$ thick slabs. Settlement strip was constructed between the existing buildings raft and the podium structure foundations to minimize the expected differential settlement between them. This strip had been casted when the building construction reached ten floors. A condition survey was performed to evaluate the structural capacity of the existing buildings. An extensive visual inspection was carried out for all the building elements and no indication of cracks/deterioration/settlement and/or damages were reported [3]. In addition, a series of core tests had been conducted for the different structural elements and Table 1 shows the results of these core tests as the mean value of the cylindrical compressive strength of concrete $\left(\mathrm{f}_{\mathrm{c}}{ }_{\mathrm{c}}\right)$ noting that the corresponding design value was $20 \mathrm{MPa}$. The conclusion was the building is still structurally sound and can be continued in use for a good margin of time without any major structural problems. The study reported also that the developer proposal to add two new thirty floors towers is structurally feasible due to the fact that the podium structure can be partially demolished along the expansion joints same as the podium foundations along the settlement strip without negative effect on the remaining structural stability.

\section{Proposed Structure Description}

The proposed structure will comprise two thirty floors towers and a set of commercial shops within the same property. Fig. 1 shows the perspective view for the new towers and the existing buildings. Towers locations in the layout plan selected to allow 
Table 1 Core test results for the existing building elements.

\begin{tabular}{|c|c|c|c|c|c|c|}
\hline \multirow{2}{*}{ Element } & \multicolumn{3}{|c|}{ Buildings } & \multicolumn{3}{|c|}{ Podium } \\
\hline & bs & Columns & Raft & Waffle & Columns & Footir \\
\hline & 1 & 60 & 30 & 30 & .50 & .60 \\
\hline
\end{tabular}

for maximum outward gulf view and inward natural light, while maintaining privacy. In addition, these locations coordinated with the structural design team to maintain the demolition lines along the expansion joints in podium level and along the settlement strip in the foundation/basement level keeping the remaining structure stable.

Table 2 shows the main features of the new towers. The typical floor height selected as $3.30 \mathrm{~m}$ to match with the existing buildings. One mechanical floor introduced at 19th floor level to satisfy the mechanical design requirements.

Table 2 Main features of the new towers.

\begin{tabular}{|c|c|c|c|c|c|}
\hline Tower & Overall Height H (m) & Least Width W (m) & $\begin{array}{l}\text { Slenderness } \\
(\mathrm{H} / \mathrm{W})\end{array}$ & Ratio No. of Typical Floors & $\begin{array}{l}\text { Typical Floor area } \\
\left(\mathrm{m}^{2}\right)\end{array}$ \\
\hline A & 107.70 & 12.52 & 8.60 & 29 & 360 \\
\hline B & 110.80 & 23.25 & 4.77 & 30 & 510 \\
\hline
\end{tabular}

Fig. 2 shows the podium overall plan indicating the demolition areas for the new towers (A and B). The new towers elevations designed to be integrated with the existing buildings elevations using the same scheme as stone cladding and strip of fair face concrete at each level.

\section{Structural System Description}

The structural floor system used for tower was conventional concrete slabs of different thicknesses supported on drop beams. Edge beam of $300 \times 800 \mathrm{~mm}$ size used to provide rigid framing between the tower external columns and to achieve the architectural

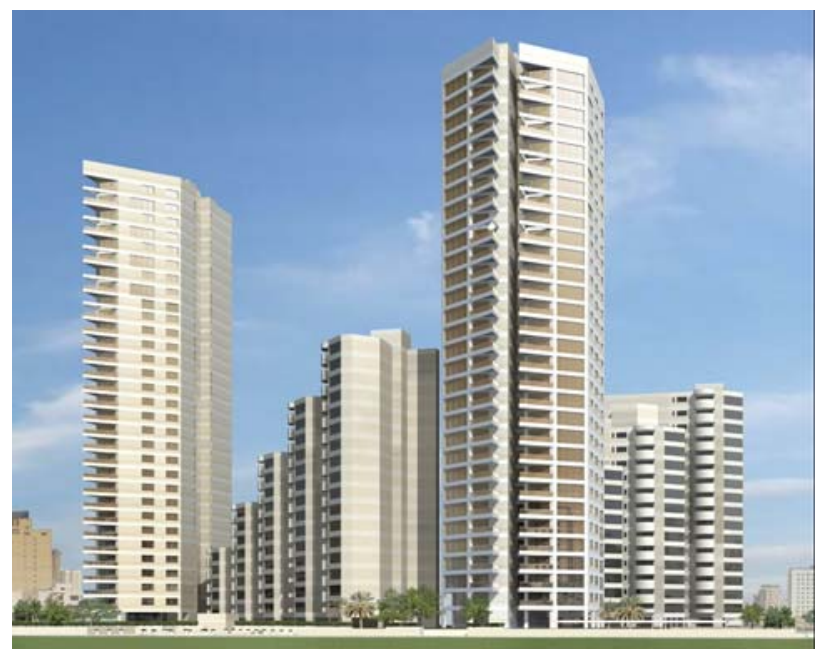

Fig. 1 Perspective view for the new towers and the existing buildings. elevation. Post-Tension (PT) slab of $320 \mathrm{~mm}$ thick used only in the large span panel where no interior columns allowed. Concrete cores around staircases and elevators space introduced to provide the main

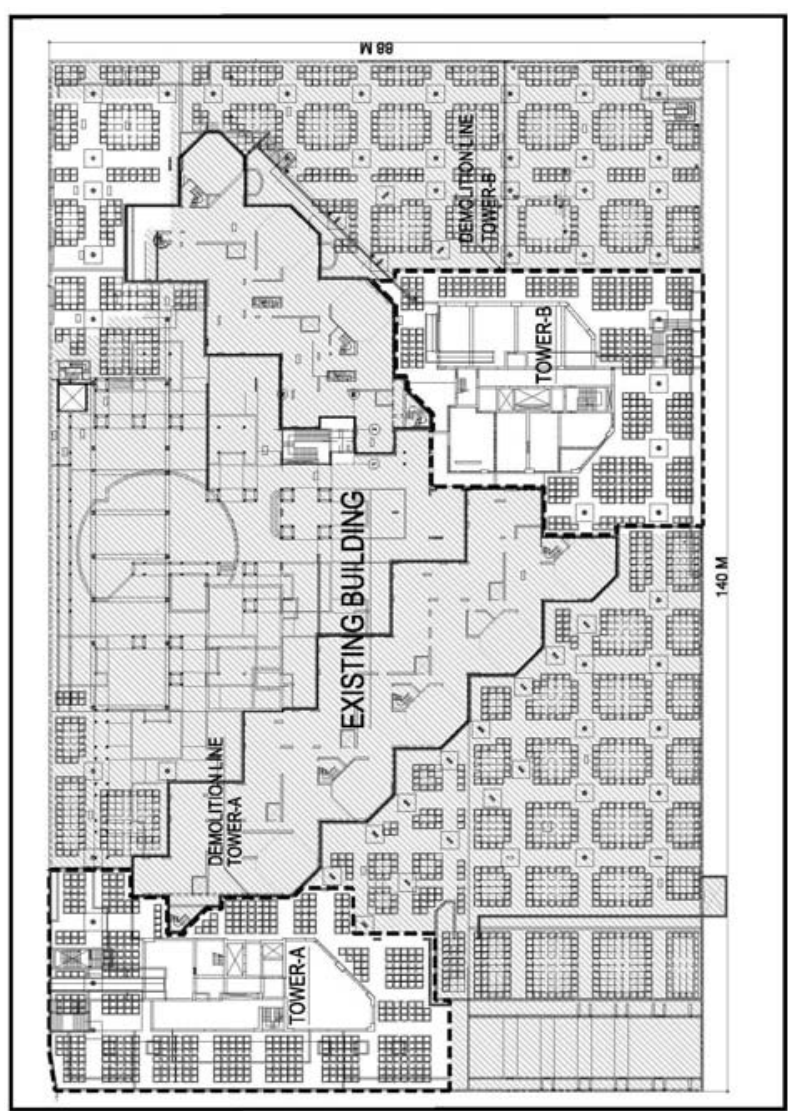

Fig. 2 The podium level overall plan indicating the demolition areas for the new towers. 


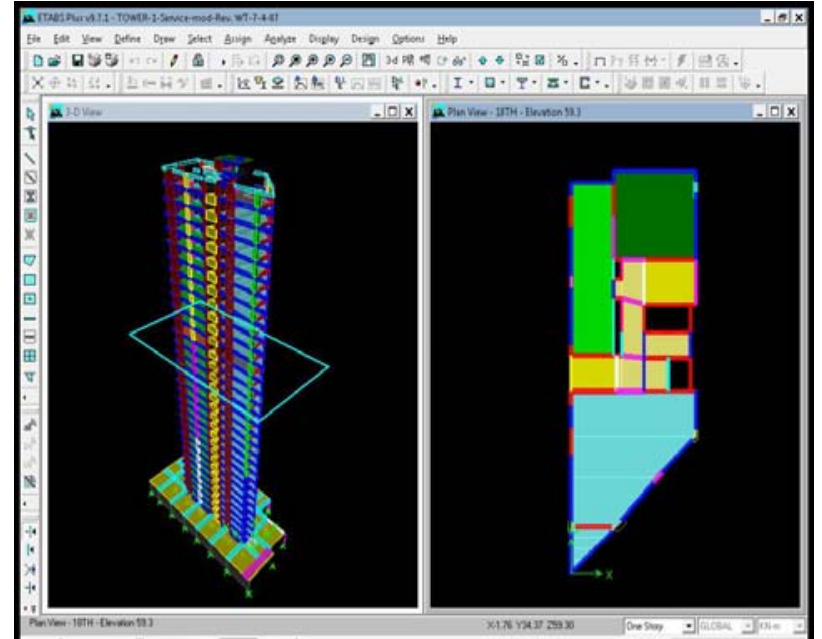

Fig. 3 Typical structural model for tower A.

lateral load resisting system. Fig. 3 shows the typical structural model for tower $\mathrm{A}$.

In tower $\mathrm{B}$, conventional concrete slabs are introduced only in the corridors between core walls while PT flat slabs of $250 \mathrm{~mm}$ thick are used in other areas without any interior drop beams. Similar to tower A, an edge beam of $300 \times 800 \mathrm{~mm}$ size is provided along the exterior building perimeter. Fig. 4 shows the typical structural model for tower B.

PT slab system is selected since it provides lighter structure in long spans, faster construction cycle, flexible for the architectural layout modifications and facilitates the coordination between different design disciplines compared to conventional concrete one.

Table 3 shows the strengths for the construction materials specified in the design of the new towers. Higher performance concrete strength was used for columns/shear walls rather than slabs/beams to minimize its sizes since they have an impact on the architectural layout.

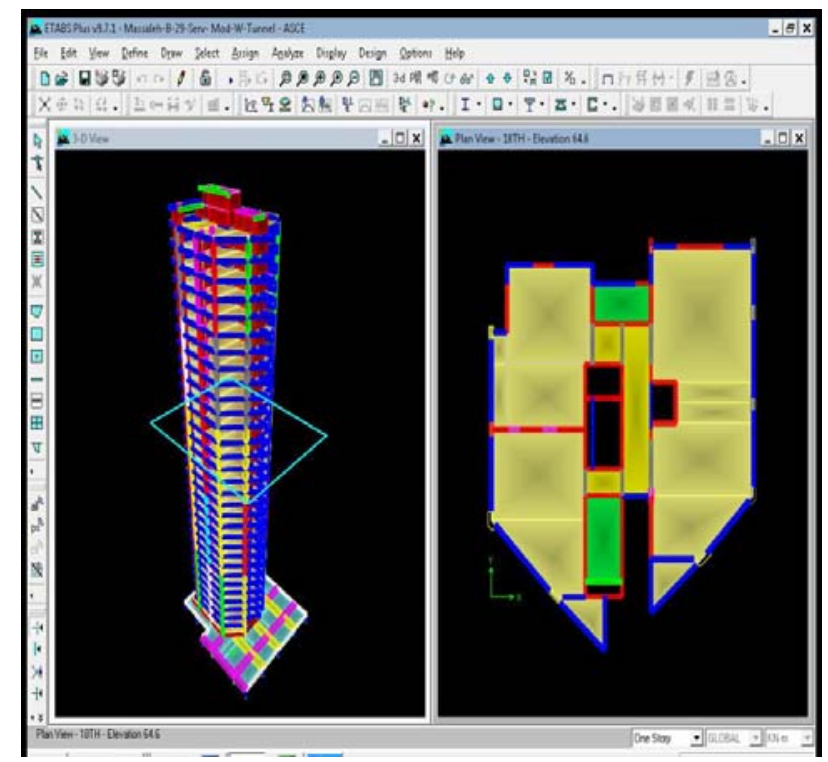

Fig. 4 Typical structural model for tower $B$.

Table 3 Construction material strengths specified in the design of the new towers.

\begin{tabular}{|c|c|c|c|c|}
\hline \multicolumn{3}{|l|}{ Concrete } & Reinforcing Steel & Low Relaxation Strands \\
\hline \multicolumn{3}{|c|}{ Cylindrical Compressive Strength $\mathrm{f}_{\mathrm{c}}{ }_{\mathrm{c}}(\mathrm{MPa})$} & Yield Strength $\mathrm{f}_{\mathrm{Y}}(\mathrm{MPa})$ & Ultimate Strength $\mathrm{f}_{\mathrm{u}}(\mathrm{MPa})$ \\
\hline Piles/Raft & Slabs/Beams & Columns/walls & All elements & PT Slabs \\
\hline 40 & 35 & 50 & 420 & 1860 \\
\hline
\end{tabular}

\section{Structural Loadings}

It is common in the residential buildings in Kuwait to use $75 \mathrm{~mm}$ floor finishing as ceramic tiles inside apartments while marble or stone flooring is used in the public areas such as entrances and lift lobbies.

Superimposed dead loads estimated at 2.20 and $2.80 \mathrm{KN} / \mathrm{m}^{2}$ for these finishes respectively while an additional equivalent uniform load of $2.50 \mathrm{KN} / \mathrm{m}^{2}$ estimated for lightweight block partitions inside apartment areas based on the architectural layout.
External stone cladding was considered to be applied on the exterior cavity walls which contain $(100+150$ $\mathrm{mm}$ ) double walls with $50 \mathrm{~mm}$ thermal insulation in-between to minimize heat transmission since Kuwait experienced very high temperature during summer times [4]. In general, live loads were used as specified in ASCE7-05 code [5] according to the type of occupancy. The three second gust wind speed based on 50 years return period and consistent with ASCE7-05 code was considered $36 \mathrm{~m} / \mathrm{sec}$ for Kuwait city as recommended by the specialist wind consultant. 
Building code procedures for wind load definition based on general assumption are usually but not always conservative and do not provide accurate wind loads because of exposure conditions, directional properties of the wind climate, complex geometry shapes, torsion, aerodynamic interaction and load combinations. Based on the professional engineering practice, it is recommended to conduct wind tunnel test for more accurate wind load definition in case of building has height more than $100 \mathrm{~m}$ or has complex geometry in plan and/or elevation or has irregular surrounding buildings may affect the wind aerodynamic flow. In our case study where the new towers were located in close proximity with the existing buildings, wind tunnel test was conducted and results shall be discussed in the next section.

\section{Wind Tunnel Test and Results}

A 1:300 scale aero-elastic model of the proposed towers and its surrounding buildings within $500 \mathrm{~m}$ diameter was constructed in the specialist wind consultant lab in order to conduct the wind tunnel test. This model must simulate the flexibility, the damping and the mass of the original structure. The structure design team of the project prepared the information such as shape and location of the building, the mass distribution and the fundamental periods of the first three modes and its anticipated displacements.

Fig. 5 shows the model used for the wind tunnel test in the lab while Table 4 summarized the input data and the test results for the new towers. Peak base loads indicated in the table are only due to wind loads and estimated based on $2 \%$ structural damping and the acceleration is the peak acceleration and calculated on the highest occupied levels based on $1.5 \%$ structural damping.

It can be concluded from the wind tunnel test results that:

(1) Tower A is more sensitive to dynamic loadings than tower $\mathrm{B}$ since its slenderness ratio is about 1.80 times that of tower B. This is reflected clearly in the fundamental periods where the first mode period of tower $\mathrm{A}$ is 1.40 times that of tower $\mathrm{B}$.

(2) Tower A experienced peak base loads due to wind in X-direction about 3.20 times that due to wind in Y-direction due to its geometry since its plan aspect ratio is about 0.39 . While tower $\mathrm{B}$ experienced peak base loads due to wind in X-direction about 0.77 that of $\mathrm{Y}$-direction since it has plan dimension aspect ratio of 0.95 .

(3) Tower A is subjected to base torsion moment about 3.0 times that of tower B due to the fact that there is an eccentricity between the centers of mass and rigidity in this tower while the same centers are very close to each other in tower $B$.

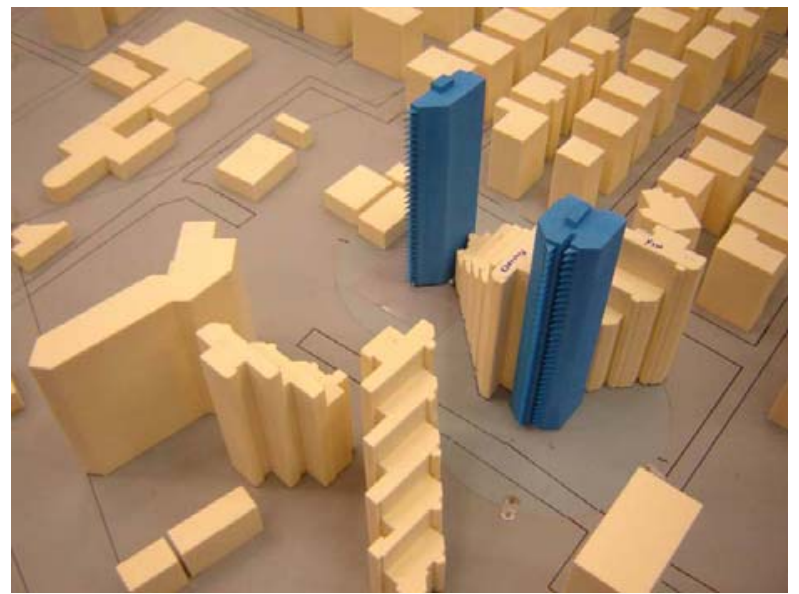

Fig. 5 Wind tunnel test model for the proposed towers with the surrounding buildings.

Table 3 Input data and wind tunnel test results for the new towers.

\begin{tabular}{llllllllll}
\hline & \multicolumn{3}{c}{ Input data } & \multicolumn{6}{c}{ Output Results } \\
\cline { 2 - 10 } Tower & \multicolumn{2}{c}{ Fundamental Periods (Sec) } & \multicolumn{3}{c}{ Peak Base loads (MN, m) } & Acceleration (milli-g) \\
\cline { 2 - 10 } & T1 & T2 & T3 & FX & FY & MX & MY & MZ & 10 years \\
\hline A & 4.0 & 3.0 & 2.8 & 6.1 & 1.9 & 125 & 392 & 22.3 & 18.5 \\
B & 2.8 & 2.5 & 1.8 & 2.0 & 2.6 & 174 & 126 & 7.40 & 6.8 \\
\hline
\end{tabular}


(4) Tower A experienced peak acceleration at the highest occupied level about 2.72 times that of tower $\mathrm{B}$ for 10 years return period and this can be mainly referred to the more dynamic sensitivity of tower A compared to tower $\mathrm{B}$ due to the difference in the slenderness ratio of these towers. In addition, peak accelerations for both towers are found within the acceptable occupant comfort level for the residential buildings.

As a final result of the wind tunnel test, 8 and 10 different distilled wind load cases are obtained for towers $\mathrm{A}$ and $\mathrm{B}$ respectively and incorporated into ETABS 3D models and considered in the analysis and design of the new towers.

\section{Structural Analysis and Design}

Three dimensional structural models built for the two towers $\mathrm{A}$ and $\mathrm{B}$ using finite element techniques through ETABS software as shown in Figs. 3 and 4 respectively. Slabs and walls were represented in the models as shell elements and the automatic mesh generation option was selected for slab elements only. The framing elements (columns and beams) were represented in the models as line elements. The stiffness modifier factors for slabs, beams, columns and shear walls were used as specified in ACI code [6] in both serviceability and ultimate cases. P-delta analysis option was selected for concrete structures. Both gravity (dead and live) and lateral (wind and seismic) loads which were described earlier in this paper were applied to the models. ETABS has advantage of automatic generation of code lateral wind and seismic loads while wind loads resulted from wind tunnel test were provided as user defined loads. A serviceability study was performed to ensure that buildings have sufficient stability to limit lateral drift due to wind at the top of the towers within the acceptable range of occupancy comfort $(\mathrm{H} / 400 \rightarrow \mathrm{H} / 600)$. In addition, the inter-story drifts which were equal to the wind lateral displacement difference for one floor divided by the floor height were found within the acceptable limits (1/500). Table 5 shows the serviceability analysis results for the new towers.

It can be concluded from the serviceability analysis results presented in Table 5 that:

(1) Both wind drift and inter-story wind drift of towers $\mathrm{A}$ and $\mathrm{B}$ were found within the acceptable limits and verify that these towers had sufficient stiffness to control the serviceability checks.

(2) Tower A experienced wind drift based on code wind load values about $57 \%$ of that resulted from wind tunnel test. This can be referred to the high slenderness ratio and the eccentricity between the mass and rigidity centers of that tower. Code wind load values can't be reliable in the case of tower A.

(3) Tower B wind drift based on code wind loads values were found higher than that resulted from wind tunnel test by about $13.5 \%$. This can be referred to the regularity and symmetry in the building geometry shape. In this case, code wind load values can be used in a conservative way.

An ultimate strength study was carried out to design the different structural elements using the ultimate load combinations as defined by ASCE7-05 code which automatically generated by ETABS software. Higher percentages of reinforcement for columns and shear walls were found in tower A compared to tower $\mathrm{B}$ due to the higher straining actions experienced by these elements in tower A.

Table 5 Serviceability analysis results for the new towers.

\begin{tabular}{llll}
\hline Tower & Wind load case & Wind drift $(\mathrm{mm})$ & Inter-story wind driftX10 \\
\hline \multirow{2}{*}{ A } & Code wind values & 128.24 & 12 \\
& Wind tunnel wind values & 225.50 & 21 \\
B & Code wind values & 40.46 & 3.5 \\
& Wind tunnel wind values & 35.66 & 3.2 \\
\hline
\end{tabular}




\section{Foundation Design}

The soil investigation report recommended cast-in-situ concrete bored piles as the most appropriate foundation system to support the new towers due to many reasons. Some of these reasons were the overstressing on the soil and the excessive settlement below the towers if raft foundation system was used. In addition, it needs to ensure that there is no impact on the existing buildings foundations due to the new constructed towers. Design of foundation was performed using the finite element method through SAFE software [7]. The option of importing geometry and analysis results of all load combinations at the foundation level directly from ETABS provides good and easy tool for foundation design. Fully piled system without considering the raft/soil interaction was the selected system in this study. Piles are represented by springs with vertical stiffness value based on $10 \mathrm{~mm}$ settlement while the horizontal stiffness value is considered as $10 \%$ of it and pile caps were represented by shell elements with automatic internal meshing. Table 6 shows the pile data (type, diameter and service load capacity) used in the foundation design of the new towers. Based on the soil profile on site, it was found more practical to fix the piles toe level on a certain strong stratum. This means that lengths of piles are different according to the pile cut-off level and the maximum pile length was found about $17 \mathrm{~m}$.

Preliminary pile load tests were conducted on testing piles up to 2.50 times its expected service load capacity to confirm that the pile parameters used in the design are correct. In addition, the working piles were tested after construction up to 1.50 times of its service capacity to ensure that the executed piles are capable to withstand the design loads and transfer them to the underneath soil strata in a safe manner by both friction and end bearing. The loads transferred from the super-structure to the piles through a set of pile caps of different thicknesses ranging from $1.0 \mathrm{~m}$ to $2.0 \mathrm{~m}$. Fig. 6 shows the connection details between the existing buildings and the new towers foundations. Secant piles of $500 \mathrm{~mm}$ diameter were used to retain soil below the existing raft and prevent any soil movement or settlement below the existing buildings

Table 6 Pile data used in foundation design of the new towers.

\begin{tabular}{lll}
\hline Pile type & Diameter $(\mathrm{mm})$ & Service load capacity $(\mathrm{kN})$ \\
\hline P1 & 700 & 1600 \\
P2 & 800 & 2250 \\
P3 & 800 & 2750 \\
P4 & 900 & 3250 \\
\hline
\end{tabular}

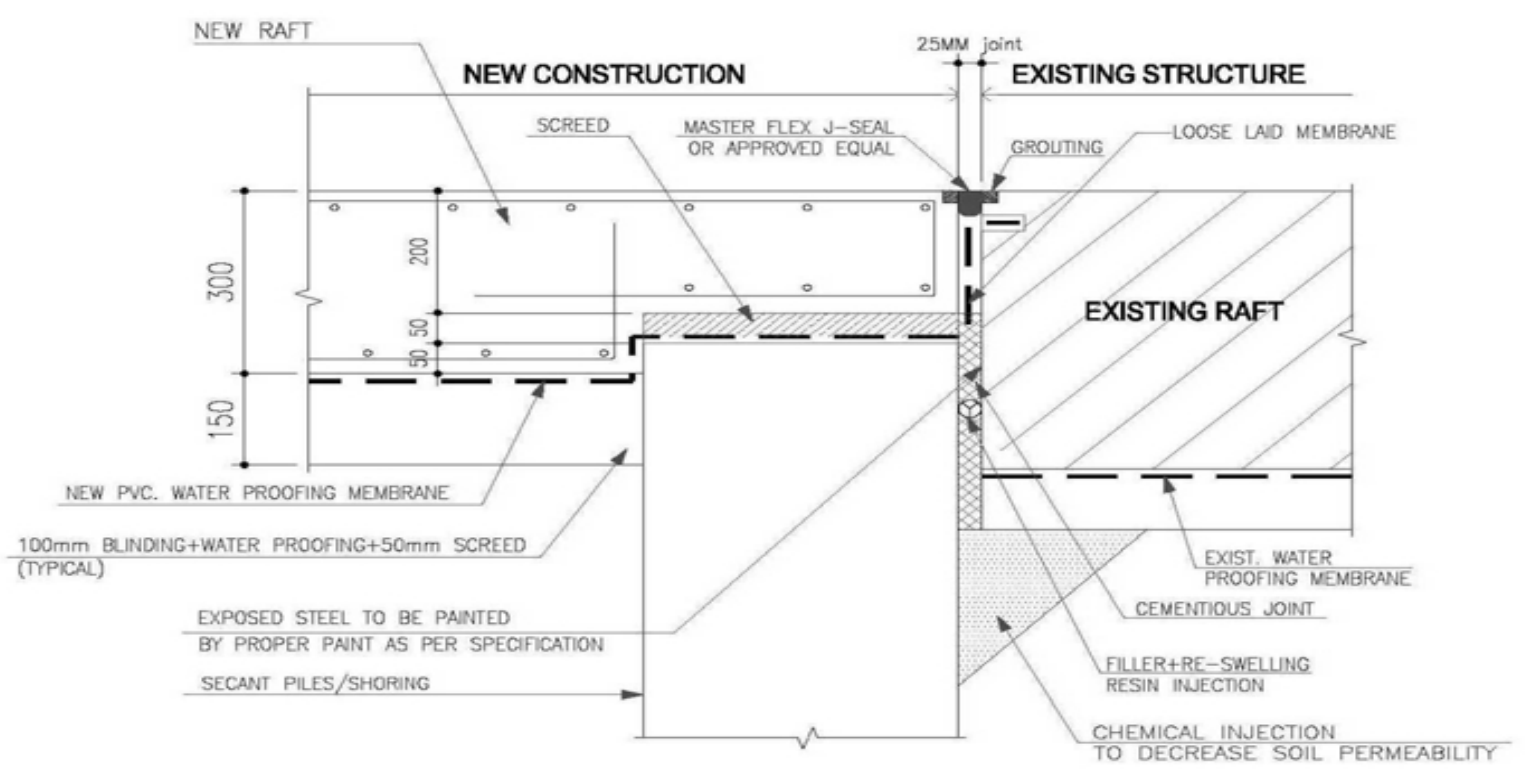

Fig. 6 The connection between the existing buildings and the new towers foundations. 
raft. Continuous monitoring for settlement and cracks in the existing buildings are recorded in daily basis. The existing building close to tower B with 18 floors height experienced about $12 \mathrm{~mm}$ progressive settlement during installation of secant piles and by investigation it was found that soil cavities was the main reason. Soil injection using cement base grout material was carried out and successfully stopped this settlement. In addition, three lines of defense were used (chemical soil injection, re-swelling resign and PVC water proofing membrane) to keep the joint at basement level water tight. This joint constructed successfully by good detailing, using reliable material selection and high quality control to guarantee its tightness.

\section{Summary and Conclusions}

A case study of concrete residential complex in Kuwait city was presented as a good example for demonstration of building slenderness ratio influence on the structural behavior of residential concrete tall buildings. Two towers of 8.60 and 4.77 slenderness ratios were presented. Wind loading was considered using both code values and wind tunnel test results. Analysis results are presented and it can be concluded from this study that:

(1) A condition survey including visual inspection, series of tests for the different structural elements and structural analysis to study the stability and status of the existing structure is necessary prior to take any decisions related to extension, demolition and/or up-grading of any existing building.

(2) The building slenderness ratio is one of the most significant factors affecting the structural behavior of high rise buildings. Tower A of slenderness ratio 8.60 experienced wind drift 6.30 times that of tower $\mathrm{B}$ which has this ratio as 4.77 using the wind tunnel test results.

(3) The building core size and location play a significant role in the structural behavior of high rise buildings. Tower A experienced 6.30 times higher wind drift, 2.72 times higher acceleration and 3.0 times higher torsion moment at building base compared to tower B due to many reasons. One of the major reasons is the eccentricity found in tower A between the centers of rigidity and mass since the building core is arranged at the edge of the building while the core of tower B is arranged at the center of the building.

(4) Wind tunnel testing is necessary in case of building has height more than $100 \mathrm{~m}$ or has complex geometry in plan and/or elevation or has irregular surrounding buildings may affect the wind aerodynamic flow for more accurate definition of wind loadings. In the other cases, code wind load values can be used in a conservative way. In tower A, wind tunnel test results provides wind drift 1.76 times higher than that resulted from code wind values while in tower $\mathrm{B}$, code wind values provide $13.5 \%$ higher wind drift compared to that resulted from wind tunnel test which confirm that wind tunnel test is necessary in case of tower A.

\section{References}

[1] T. A. Awida, Recent practices of analysis and design of high rise buildings in Kuwait: Case study, in: Proceedings of 2nd ACI (Kuwait Chapter) International Conference on Design and Sustainability of Structural Concrete in Middle East, State of Kuwait, 12-14 March, 2007, pp. 359-370.

[2] Computer and Structures Incorporation (CSI), Extended Three Dimensional Analysis of Building Systems (ETABS) software Ver.9.7:2009, University Avenue, Berkeley, California, USA.

[3] T. A. Awida, Partial demolition and extension of Kuwait medical college building, ASCE Journal of Architectural Engineering 8 (1) (2002) 2-6.

[4] T. A. Awida, Study for the structural behavior of low/medium/high rise reinforced concrete residential buildings in Kuwait, in: Proceedings of the Fourth International Conference on Structural Engineering, Mechanics and Computation (SEMC 2010), Cap Town, South Africa, 6-8 Sep., 2010.

[5] American Society of Civil Engineers (ASCE), Minimum Design Loads for Buildings and Other Structures Code: ASCE7-05, New York, USA.

[6] American Concrete Institute (ACI), Building Code Requirements for Structural Concrete and Commentary: ACI 318-05, Farmington Hills, USA.

[7] Computer and Structures Incorporation (CSI), Slab Analysis by the Finite Element Method (SAFE) software ver. 12.3.0:2010, University Avenue, Berkeley, California, USA. 